\title{
Crystalline nature of the iridescent particles in hypermature cataracts
}

\author{
Anne M V Brooks, Ross H Drewe, Glenys B Grant, Timothy Billington, William E Gillies
}

The Royal Victorian Eye and Ear Hospital, 32 Gisborne Street, East Melbourne, Victoria 3002, Australia

A M V Brooks

R H Drewe

G B Grant

W E Gillies

\section{St Vincent's Hospital,} Fitzroy, Victoria 3065, Australia

\section{Department of Anatomical Pathology R H Drewe}

Department of Chemical Pathology

$T$ Billington

\section{Correspondence to:}

Dr W E Gillies, 82 Collins Street, Melbourne, Victoria 3000, Australia.

Accepted for publication 22 February 1994

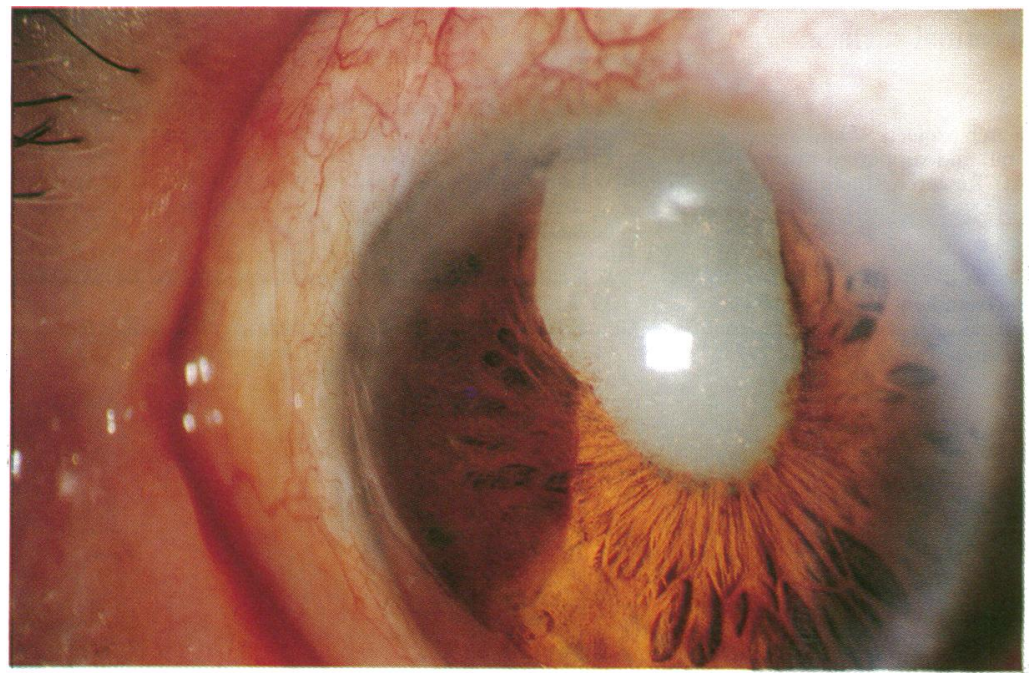

Figure $1 A$ Slit-lamp appearance of right eye showing hypermature cataractous lens. of the relation between phacolytic glaucoma and hypermature cataract to establish whether the crystals around the nucleus are cholesterol or oxalate. Recently we have been able to examine these crystals in aspirate of the liquefied cortex of a hypermature cataract.

\section{Case report}

A male patient, aged 77 years, presented to us with a hypermature cataract. He had previously undergone bilateral trabeculectomies for bilateral cyclitic glaucoma uncontrolled by topical medication. The right eye subsequently needed reoperation with needling of the bleb and later repair of the bleb. On slit-lamp examination the dense nucleus of the lens was displaced downward and liquefied cortex with brilliant iridescent particles was seen within the lens capsule above the nucleus (Fig 1A). The iridescent particles were demonstrated within the lens on specular microscopy with a morphology strongly suggestive of cholesterol crystals (Fig 1B). During a right extracapsular extraction some of the liquefied cortex was aspirated and a sample of aqueous was also obtained. Subsequently the eye settled satisfactorily but a total retinal detachment was present with preretinal proliferation and retraction. verified. ${ }^{910}$ Similar particles occur around the lens nucleus in hypermature cataracts and have been thought to be calcium oxalate by some workers. ${ }^{511}$ It is important for our understanding

\section{Pathological investigation}

Wet mounts of the fluid obtained by anterior chamber paracentesis showed no cells or crystals. The liquefied lens cortex contained numerous flat, rhomboidal crystals, many of which were notched at the corner or were L-shaped (Fig 2), but there were no inflammatory cells. The morphology of the crystals was characteristic of cholesterol or cholesterol ester crystals, and this was confirmed by semiquantitative thin layer chromatography (TLC) using a solvent system designed for cholesterol and its esters. This showed a large spot with correct mobility for unesterified cholesterol, a barely visible spot for esters, and a barely visible spot with mobility compatible with phospholipid. Quantitative in vitro assay showed unesterified cholesterol $0.38 \mu \mathrm{mol}$ in the thawed assay sample with estimated concentration of $1900 \mu \mathrm{mol} / \mathrm{l}$ (estimated sample volume $0.2 \mathrm{ml}$ ) and assay detection limit of $400 \mu \mathrm{mol} / 1$. Esters of cholesterol and phospholipid were below the assay sensitivity limit. This quantitative analysis guarantees that at least $75 \%$ to $80 \%$ of the sample consists of unesterified cholesterol, the 'proved' percentage. The TLC results indicate that the correct figure is much higher, perhaps $99 \%$ or more, but this depends on visual inspection and is only semiquantitative. The 'proved' upper limit on the percentage figure is limited only because the sensitivity limit of the quantitative assay is being approached, not because these two tests differ in their results. The small amount of phospholipid present is compatible with diffusion into the lens, or origin from breakdown of lens fibre plasma membranes within the lens. The latter seems more likely. Other substances which have been postulated as the cause of intralenticular crystals, such as oxalates, do not move at all in this solvent system and cannot be confused with the cholesterol spots.

Histological sections of the lens nucleus removed by extracapsular extraction showed compact lens fibres with no evidence of cataractous degeneration (except at the corticonuclear boundary) and no lipid clefts. The lens cortex 


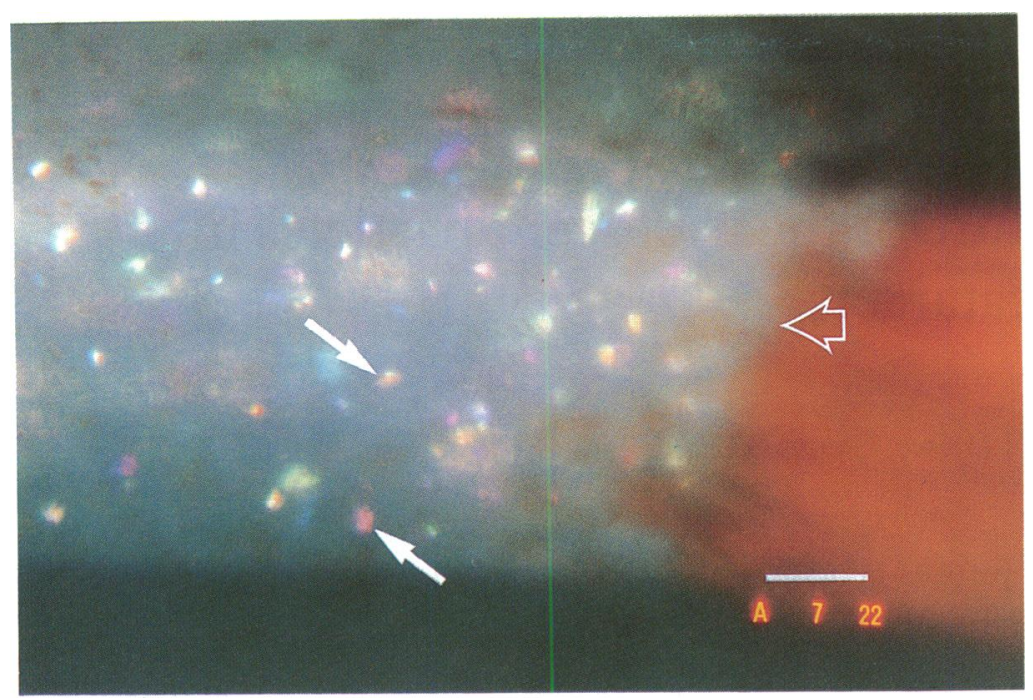

Figure 1B Specular microscopy of the lens showing iridescent particles many with the rhomboidal structure with notched corner typical of cholesterol crystals (closed arrows). Posterior synechiae at pupil margin shown by open arrow. Bar $=100 \mu \mathrm{m}$.

was liquefied and therefore did not appear in the tissue sections. As the crystals were only present in this liquefied cortex they did not appear in the tissue sections.

\section{Comment}

It is important not to use alcohol or xylol when preparing material thought to contain cholesterol as alcohol dissolves cholesterol. If the crystals are not dissolved, the rhomboidal form of cholesterol crystals will only be seen if they are arranged in an optimal plane to the observer.

Examination of the aspirate from the liquefied cortex in this case confirms that the iridescent granules in hypermature cataracts are cholesterol crystals. It also strongly suggests that similar granules seen in immature cataracts are due to cholesterol crystals. The origin of this cholesterol in the lens, which consists mostly of protein filled lens fibres is enigmatic. The cholesterol may originate from the cell membranes; however, if this were so a much higher concentration of phospholipid would be expected, but it is possible that this may have diffused out of the lens. It is more likely that cholesterol diffuses into the lens from fine leaking new vessels lying close to the lens in the iris or on the retinal surface.

This work was carried out under research projects 92 and 99 of the Royal Victorian Eye and Ear Hospital, and supported in part by the Eye, Ear, Nose and Throat Research Institute, East Melbourne, Victoria, Australia.

1 Kaufman SI. Morgagnian cataracts and their complications: with report of a case of spontaneous rupture of the lens capsule causing secondary glaucoma. Arch Ophthalmol 1933; 9: $56-63$.

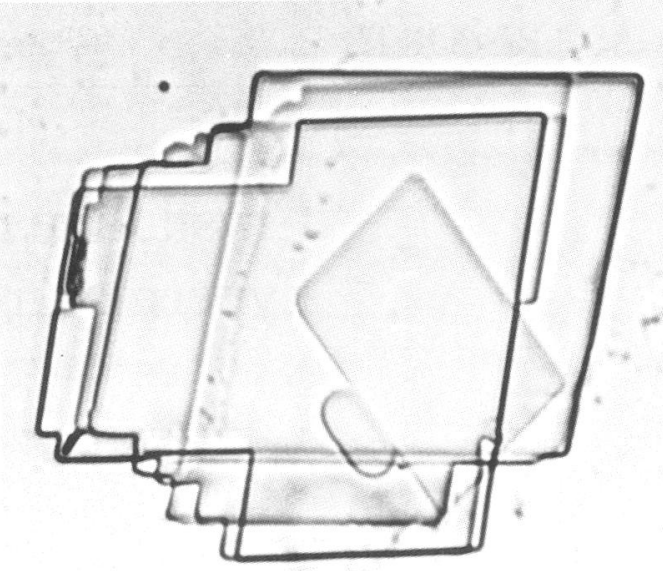

Figure 2A Wet mount of the fluid cortical material showing typical flat rhomboidal cholesterol crystals, some with notched corners (magnification $\times 300$ ).

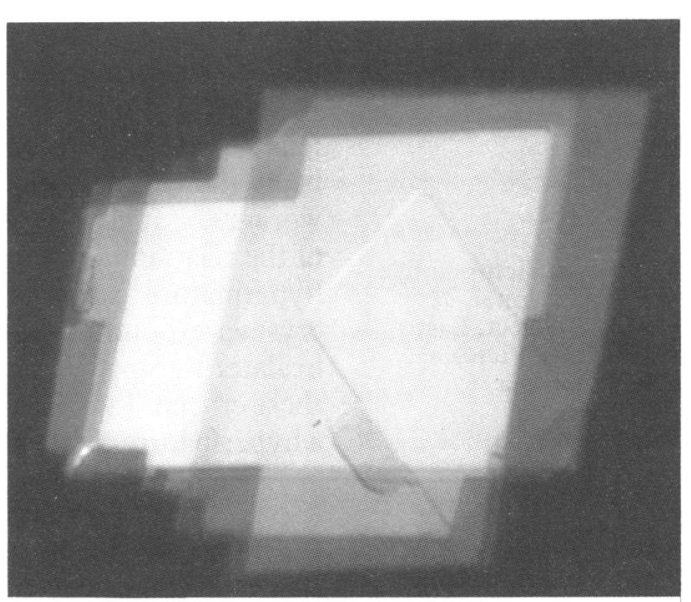

Figure $2 B$ In polarised light the crystals were weakly birefringent (magnification $\times 300$ ).

2 Knapp HC. Spontaneous rupture of the lens capsule in hypermature cataract causing secondary glaucoma. $A m \mathcal{F}$ Ophthalmol 1937; 20: 820-1.

3 Irvine SR, Irvine AR Jr. Lens-induced uveitis and glaucoma. Part III. 'Phacogenetic glaucoma': lens-induced glaucoma; mature or hypermature cataract; open iridocorneal angle. Am 7 Ophthalmol 1952; 35: 489-99.

4 Hubbersty FS, Gourlay JS. Secondary glaucoma due to spontaneous rupture of the lens capsule. Br $\mathcal{F}$ Ophthalmol
$1953 ; 37: 432-5$.

5 Flocks M, Littwin CS, Zimmerman LE. Phacolytic glaucoma: a clinicopathologic study of one hundred thirty-eight cases of glaucoma associated with hypermature cataract. AMA Arch Ophthalmol 1955; 54: 37-45.

6 Ballen PH, Hughes WL. Spontaneous rupture of lens capsule in hypermature (Morgagnian type) cataract. Am f Ophthalmol 1955; 39: 403-5.

7 Leigh AG. Lens induced uveitis. Trans Ophthalm Soc UK 1955; 75: 51-65.

8 Safar K. Cholesterinausstreuung in der vorderen Augenkammer als Ursache von Glaukom bei überreifem Altersstar. Ztschrf Augenheilkd 1928; 64: 46-50.

9 Brooks AMV, Grant G. Gillies WE. Comparison of specular microscopy and examination of aspirate in phacolytic glaucoma. Ophthalmology 1990; 97: 85-9.

10 Hurley IWJ, Brooks AMV, Reinehr DP, Grant GB, Gillies WE. Identifying anterior segment crystals. $\mathrm{Br} \mathcal{F}$ Ophthalmol 1991; 75: 329-31.

11 Goldberg MF. Cytological diagnosis of phacolytic glaucoma utilizing millipore filtration of the aqueous. BrF Ophthalmol 1967; 51: 847-53. 